\title{
FULL - SCALE TESTS ON COLD-FORMED STEEL PITCHED-ROOF PORTAL FRAMES WITH BOLTED JOINTS
}

\author{
D. Dubina ${ }^{1 *}$, A. $\operatorname{Stratan}^{1}$ and Zs. Nagy ${ }^{2}$ \\ ${ }^{I}$ Politehnica University of Timisoara, Faculty of Civil Engineering, \\ Department of Steel Structures and Structural Mechanics, \\ str. Ioan Curea nr.1, Timisoara 300224, Romania \\ tel/fax: ++40.256 .403932$ \\ ${ }^{2}$ Gordias SRL, Bucharest, Romania \\ *(Corresponding author: E-mail: dan.dubina@ct.upt.ro)
}

\begin{abstract}
The paper summarises the results of an experimental program carried out in order to evaluate the performance of pitched roof cold-formed steel portal frames of back-to-back channel sections and bolted joints. Three different configurations of ridge and eaves joints were tested. The behaviour and failure mechanisms of joints were observed in order to evaluate their stiffness, strength and ductility. Joints between cold-formed members with bolts in the web only result in a reduction of joint moment capacity and premature web buckling. The component method was applied in order to characterise the joint stiffness and moment capacity for the purpose of frame analysis and design. The influence of joints characteristics on the global frame response under lateral (seismic) loads was analysed by considering three connection models. Full-scale tests were performed on cold-formed pitched-roof portal frames. The paper presents experimental observations and comparison to numerical predictions of frame response.

Keywords: Cold formed construction, pitched roof portal frames, joint behaviour, full-scale tests
\end{abstract}

\section{INTRODUCTION}

Previous studies by Lim and Nethercot [1] and Chung and Lau [2] showed that bolted joints in cold formed steel portal frames have a semi-rigid behaviour. Also, these types of joints are partially resistant (Lim and Nethercot [3]). When bolts are installed only on the web of cold-formed section, the local buckling is made more critical by stress concentrations, shear lag and bearing deformations around bolt holes (Dundu and Kemp [4]), reducing the moment resistance well below the moment resistance of the effective cross-section. In case of usual cold-formed steel sections, both tests and numerical simulations show that elastic-plastic elongation of bolt-holes is by far the most important component controlling the stiffness and capacity of such type of connections (Lim and Nethercot [1], Yu et al. [5]). The contribution of other components, such as flanges in tension and compression due to bending action, and the web in shear due to transverse action is significantly lower.

The global behaviour of cold-formed steel portal frames of bolted joints was studied experimentally by Lim [6], Dundu and Kemp [4], and Kwon et al. [7]. All these studies provided evidence of the crucial importance of joint performance on the global response of frames.

In present paper, the influence of joint characteristics on the global behaviour of cold-formed pitched-roof portal frames is investigated. An experimental program on ridge and eaves joints was carried out. Detailed results on joint behaviour are reported elsewhere (Dubina et al. [8]). Based on experimental results, a calculation procedure based on the component method (EN1993-1-8 [9]) was adapted to cold-formed joints. Joint stiffness and moment capacity obtained using the component method is used to develop a joint model for global structural analysis. Two full-scale tests on cold-formed pitched-roof portal frames with bolted joints were performed, with the primary objective to assess their performance under horizontal (seismic) loading. The results of the experimental investigation are presented and experimental response is compared to analytical predictions of frame response. 


\section{SUMMARY OF TESTING PROGRAM ON JOINT SPECIMENS}

\subsection{Specimens}

In order to be able to define realistic specimen configurations a simple pitched roof portal frame was first designed with the following configuration: span $12 \mathrm{~m}$; bay $5 \mathrm{~m}$; eaves height $4 \mathrm{~m}$ and roof angle $10^{\circ}$. This frame was subjected to loads common in the Romanian design practice: self weight $0.35 \mathrm{kN} / \mathrm{m}^{2}$ (with a partial safety factor of $\gamma_{\mathrm{ULS}}=1.1$ for the ultimate limit state), technological load $0.15 \mathrm{kN} / \mathrm{m}^{2}\left(\gamma_{U L S}=1.1\right)$ and snow load $0.72 \mathrm{kN} / \mathrm{m}^{2}\left(\gamma_{U L S}=2.0\right)$. These loads were totalling approximately $10 \mathrm{kN} / \mathrm{m}$ uniformly distributed load on the frame. The frame was analysed and designed according to EN 1993-1-3 (2001) 0 rules. The size of knee and ridge specimens and testing setup were chosen to obtain in the connected members a distribution of bending moment similar to the one observed in the designed structure.

The elements of the portal frame were made from back-to-back built up sections made of Lindab $\mathrm{C} 350 / 3.0$ profiles (yield strength $f_{y}=350 \mathrm{~N} / \mathrm{mm}^{2}$ ). Using these cross section dimensions, three alternative joint configurations were designed (see Figure 1 and Figure 2), using welded bracket elements $\left(\mathrm{S} 235: f_{y}=235 \mathrm{~N} / \mathrm{mm}^{2}\right)$

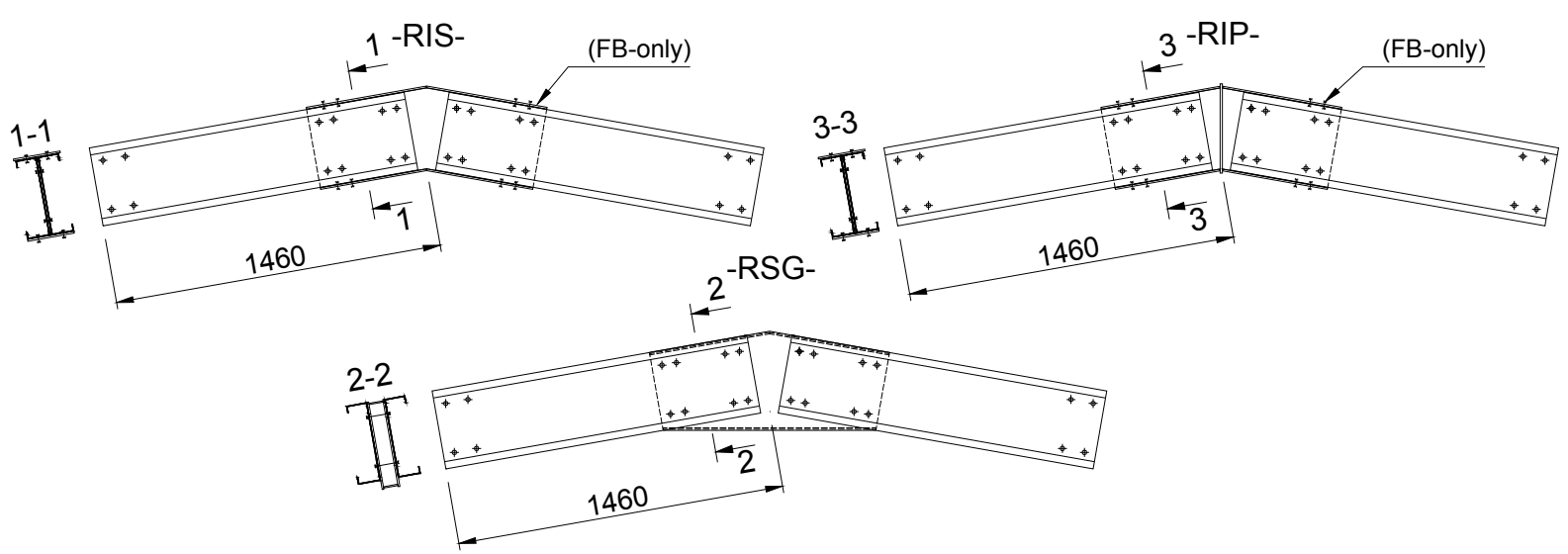

Figure 1. Configurations of Ridge Joints
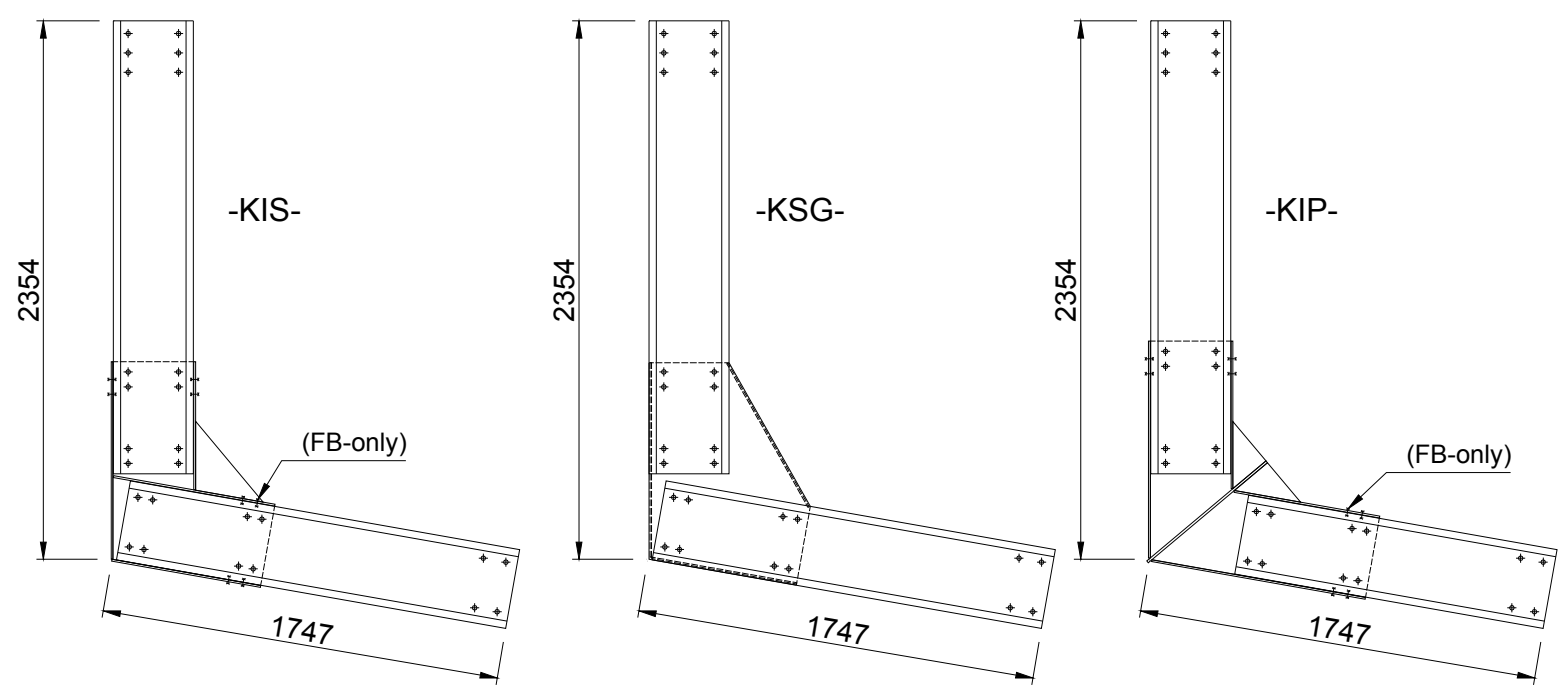

Figure 2. Configurations of Knee Joints 
The connecting bolts are subjected to shear and their design was carried out assuming the rotation of the joint around the centroid of the bolt group and a linear distribution of forces in each bolt, proportional to their distance from the centre of rotation. The joints were designed to resist the bending moment in the beam, at the location of the centroid of the bolt group.

One group of specimens (KSG and RSG) used spaced built-up gussets. In this case, bolts were provided only on the web of the $\mathrm{C} 350$ profile. In the other cases, where two different details were used for the connecting bracket - i.e. welded I sections only (KIS and RIS), and welded I section with plate bisector (KIP and RIP), respectively - bolts were provided on the web only, or both on the web and the flanges. Joints where bolts were provided on the web and on flanges were denoted by FB letters (see Table 1).

Table 1. Tests on Joint specimens

\begin{tabular}{|c|c|c|}
\hline Element type & Code & Loading type \\
\hline \multirow{3}{*}{$\begin{array}{l}\text { RIS (Ridge } \\
\text { connection with I } \\
\text { Simple profile) }\end{array}$} & RIS-FB-M & Monotonic \\
\hline & $R I S-F B-C 1^{*}$ & Cyclic: modified ECCS \\
\hline & $R I S-F B-C 2^{*}$ & Cyclic: low cycle fatigue \\
\hline \multirow{3}{*}{$\begin{array}{l}\text { RSG (Ridge } \\
\text { connection with } \\
\text { Spaced Gusset) }\end{array}$} & RSG-M & Monotonic \\
\hline & RSG-C1 & Cyclic: ECCS procedure \\
\hline & RSG-C2 & Cyclic: Modified ECCS \\
\hline \multirow{3}{*}{$\begin{array}{l}\text { RIP (Ridge } \\
\text { connection with I } \\
\text { profile and end Plate) }\end{array}$} & RIP-M & Monotonic \\
\hline & RIP-M & Monotonic \\
\hline & RIP-C1 & Cyclic - ECCS proc. \\
\hline \multirow{3}{*}{$\begin{array}{l}\text { KSG (Knee } \\
\text { connection with } \\
\text { Spaced Gusset) }\end{array}$} & KSG-M & Monotonic \\
\hline & KSG-C1 & Cyclic - Modified ECCS \\
\hline & KSG-C2 & Cyclic - Low cycle fatigue \\
\hline \multirow{3}{*}{$\begin{array}{l}\text { KIS (Knee connection } \\
\text { with I Simple profile) }\end{array}$} & KIS-M & Monotonic \\
\hline & $K I S-F B-M^{*}$ & Monotonic \\
\hline & $K I S-F B-C^{*}$ & Cyclic - Modified ECCS \\
\hline \multirow{3}{*}{$\begin{array}{l}\text { KIP (Knee connection } \\
\text { with I profile and end } \\
\text { Plate) }\end{array}$} & KIP-M & Monotonic \\
\hline & $K I P-F B-M^{*}$ & Monotonic \\
\hline & $K I P-F B-C^{*}$ & Cyclic - Modified ECCS \\
\hline
\end{tabular}

*FB Specimens (RIS, RIP, KIS, KIP) with supplementary bolts on the flange

\section{$2.2 \quad$ Test Setup}

Monotonic and cyclic experiments were performed for each specimen typology, all specimens being tested statically. Figure 3 shows the test setup and specimen instrumentation. In the knee connection tests, a short tie was used to prevent vertical displacements of the joint. For monotonically loaded specimens the loading velocity was approximately $3.33 \mathrm{~mm} / \mathrm{min}$, and the "yield" displacement $\left(\mathrm{v}_{\mathrm{y}}\right)$ was determined according to the ECCS [11] procedure, as the displacement corresponding to the intersection of the initial stiffness line and another line with a slope of $10 \%$ of the initial stiffness (see Figure 4a). For the cyclic tests several alternative loading procedures were used: (1) the standard ECCS cyclic procedure (see Figure 4b), (2) a modified cyclic procedure, suggested by the authors, which is based on the ECCS proposal (see Figure 4c) and (3) a cyclic procedure for low cycle fatigue. The ECCS loading procedure consists of four initial cycles in the elastic range, followed by groups of three inelastic cycles at $\pm 2 v_{y}, \pm 4 v_{y}, \pm 6 v_{y}$, etc. The inelastic demand imposed on cold-formed specimens following this procedure is too severe, the specimen failing during the first inelastic cycle at $\pm 2 \mathrm{v}_{\mathrm{y}}$. To overcome this problem, a modified procedure was used, that consisted of four initial cycles in the elastic range, followed by groups of three inelastic cycles at $\pm 1.2 \mathrm{v}_{\mathrm{y}}, \pm 1.4 \mathrm{v}_{\mathrm{y}}, \pm 1.6 \mathrm{v}_{\mathrm{y}}$, etc. 

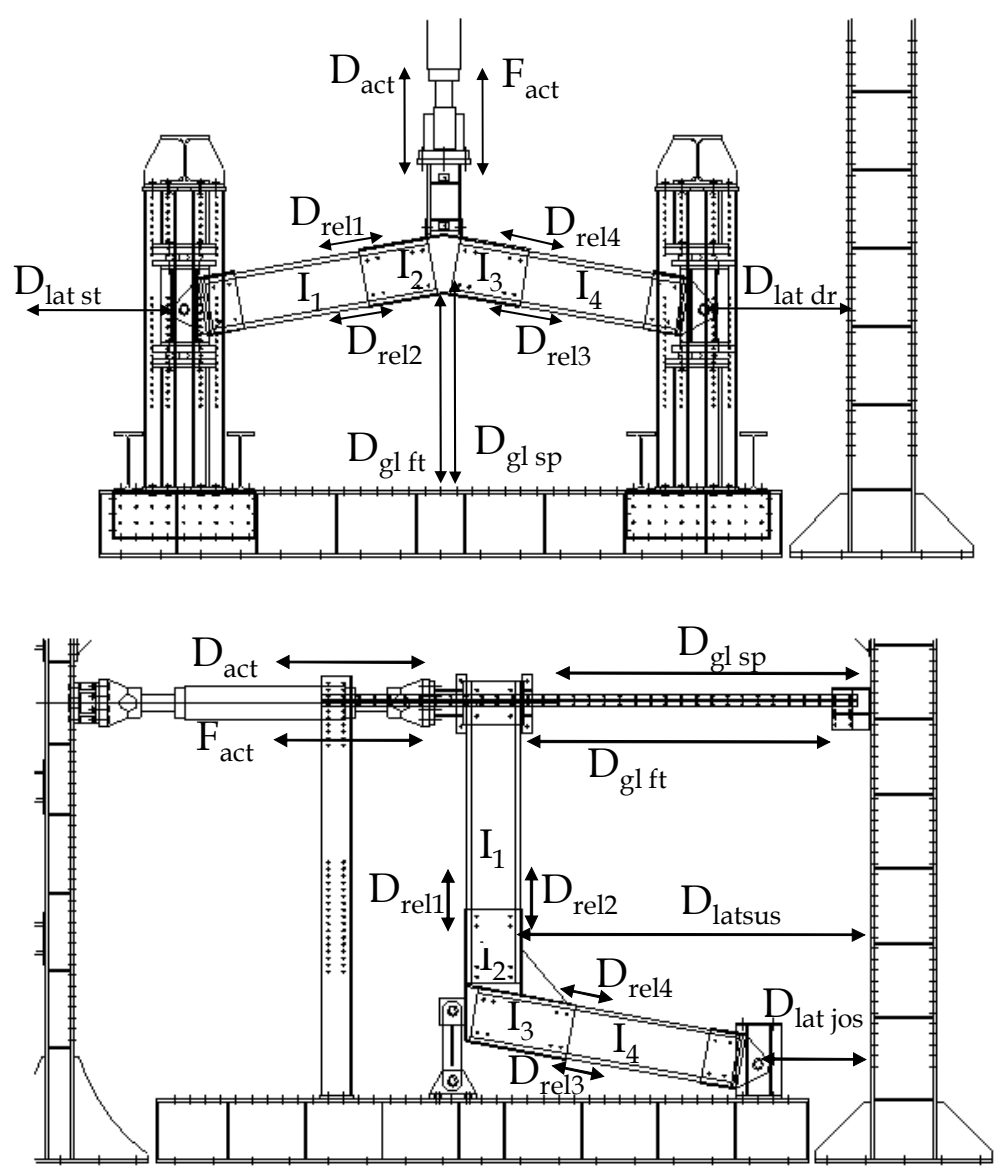

Figure 3. Loading Scheme and Instrumentation

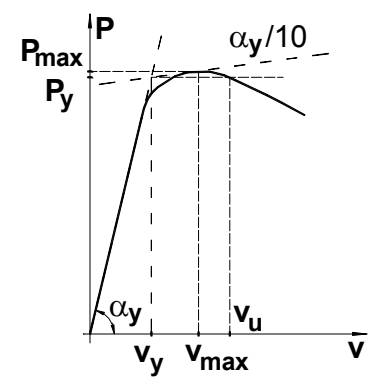

(a)

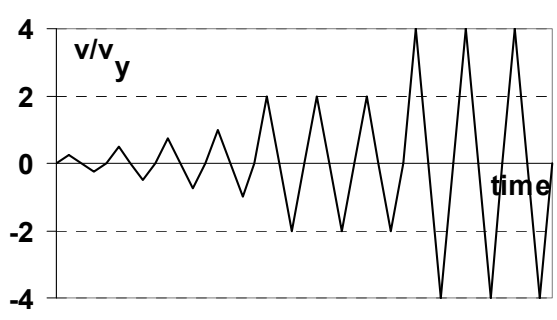

(b)

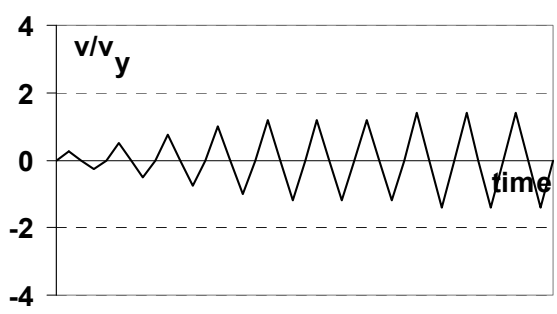

(c)

Figure 4. ECCS Procedure for Determining the Yield Displacement (a);

ECCS Loading Procedure (b) and Modified Loading Procedure (c)

\subsection{Monotonic Tests}

The monotonic tests identified failure modes of the different joint typologies. All specimens had a failure due to local buckling of the cold formed profiles; however two distinctive modes were identified for specimens with flange bolts and those without (Figure 5; Figure 6). 


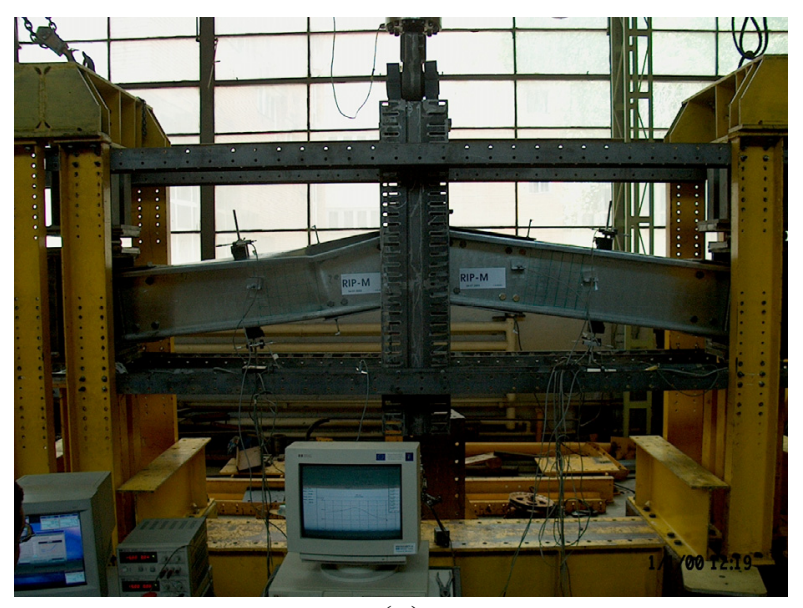

(a)

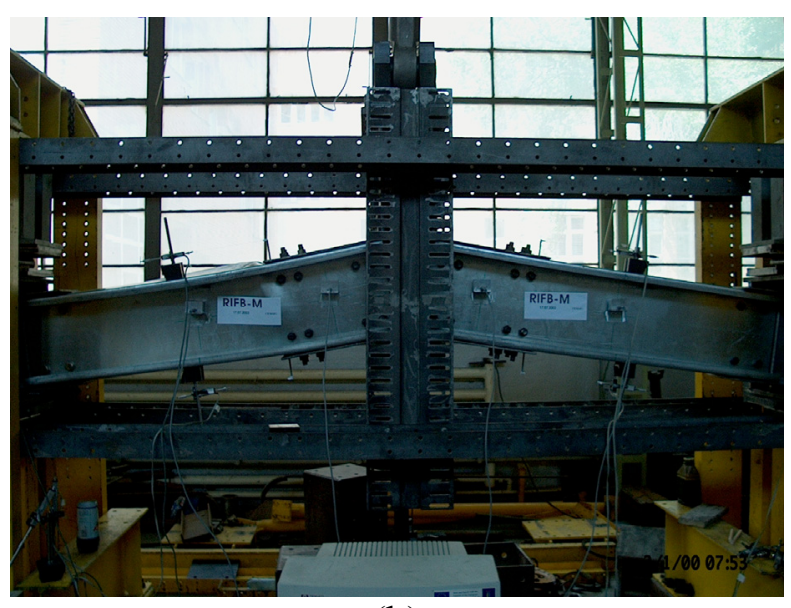

(b)

Figure 5. Failure of Ridge Specimens RIP-M (a) and RIS-FB-M (b)

If no bolts are provided on the flange of profiles, initially minor bearing elongation of the bolt holes were observed, the failure being due to stress concentration in the vicinity of outer bolt row. The resulting concentration of compressive stress in the web of the $C$ profile causes in the ultimate stage local buckling followed suddenly by web-induced flange buckling. This phenomenon occurred in a similar way in the case of RSG and KSG specimens. No important differences were observed between specimens where no bolts were provided on the flanges. In the case of the specimens with flange bolts, the stresses concentrated in the vicinity of the outer bolt row on the flange. In this case no initial elongation of the bolt holes were observed; the buckling was firstly initiated in the flange, and only later was extended into the web.

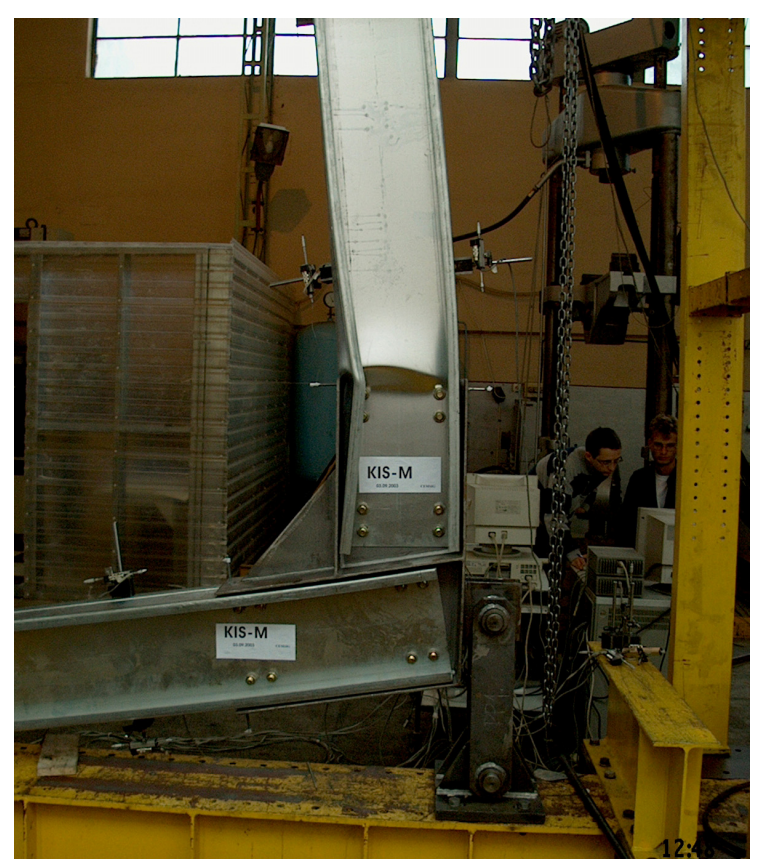

(a)

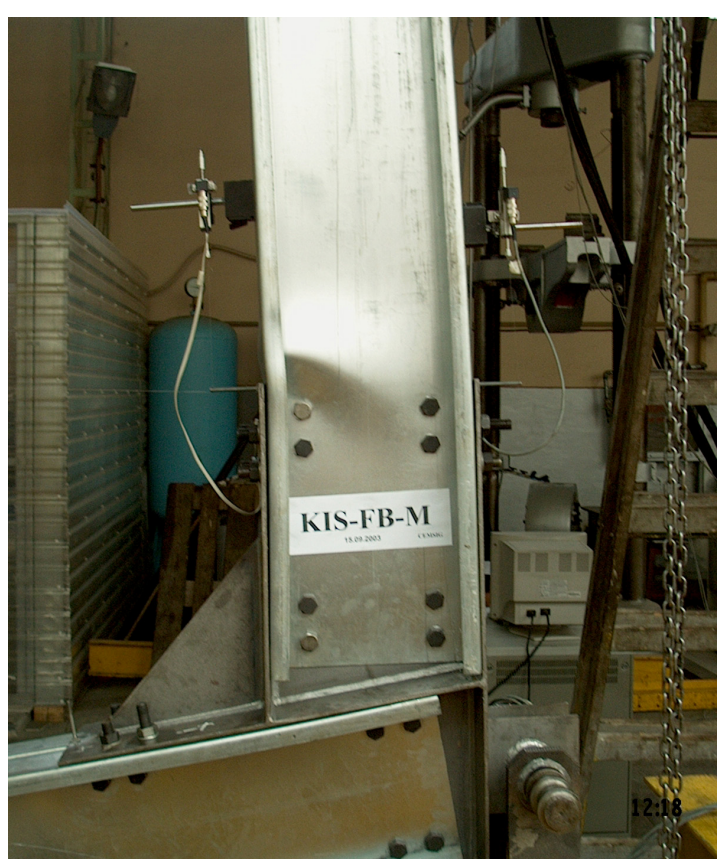

(b)

Figure 6. Failure of Knee Specimens KIS-M (a) and KIS-FB-M (b) 


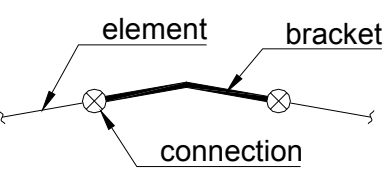

(a)

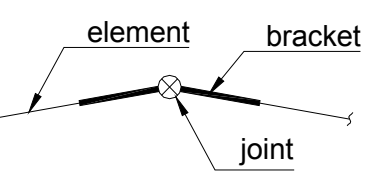

(b)

Figure 7. Two Possible Models for Ridge Joints: Detailed (a) and Simplified (b)

To account for the flexibility of the bolted connection in structural analysis, two models are possible: one which considers both connections independently (see Figure 7a), and a simplified one, which considers the characteristics of the connection concentrated in one joint only (see Figure 7b). The former is believed to represent more exactly the real behaviour of the assembly, while the latter has the advantage of simplicity. Similar models can be used for knee joint configurations. Moment-rotation relationships characterising the connection response were derived for both the left and right ridge connections (beam and column connection in the case of knee joins). Moments were computed at the end of the bracket. The corresponding relative rotation between the bracket and the connected element $\theta_{C}{ }^{*}$ was determined from acquired data, so as to represent both the flexibility of the connection (due to bolt bearing) and post-buckling deformations in the element (Dubina et al. [8]). For the simplified joint representation (as in Figure $7 \mathrm{~b}$ ), both moment $\left(M_{j}\right)$ and rotations were considered at the intersection of the element centrelines.

Comparative experimental curves for ridge and knee connections are presented in Figure 8a and Figure 9. There are no significant differences among the specimens without flange bolts (RSG-M, RIP-M, and KSG-M, KIS-M). This could be explained by the higher stiffness and capacity of the connecting bolts compared to the other components of the joint. On the other hand, there is an important gain in load bearing capacity and the initial joint stiffness when bolts are installed also on the flanges, although this joint type is more difficult to fabricate (RIS-FB-M and KIS-FB-M).

In Table 2 the yield and ultimate rotation $\left(\theta_{C, y}{ }^{*} ; \theta_{C, u}{ }^{*}\right)$, the initial stiffness $\left(K_{\text {ini } C}\right)$, and the maximum bending moment $\left(M_{C, \max }\right)$ are presented and compared for all monotonically tested specimens, for the failed connection. The initial stiffness was determined by a linear fit of moment-rotation values between 0.25 and 0.9 of the maximum moment. The lower-bound limit $(0.25)$ was chosen different from zero in order to eliminate the effect of initial slip due to tolerance of bolt-holes. This initial slip is believed to be ineffective in the real structure, due to loading-unloading cycles under service loads. The upper-bound limit (0.9) was considered empirically as a limit of elastic response of the connection. Yield rotation was determined as the point on the initial stiffness line corresponding to maximum moment. Ultimate rotation was defined as the one corresponding to a $10 \%$ drop of moment capacity relative to the maximum moment. Figure $8 \mathrm{~b}$ presents graphically determination the initial stiffness, yield rotation and ultimate rotation for the RIS-FB-M specimen.

Obviously, the specimens with unbolted flanges that failed prematurely by web buckling due to stress concentration around the outer bolt rows, would be the weakest part of portal frames. Consequently, this joint typology is not recommended to be used in practice. 
Table 2. Monotonic Results: Parameters of Connection Moment-Rotation Curves

\begin{tabular}{|l|l|l|l|l|l|}
\hline Specimen & $\begin{array}{l}\mathrm{K}_{\text {iniC }} \\
\mathrm{kNm} / \mathrm{rad}\end{array}$ & $\begin{array}{l}\theta_{\mathrm{C}, \mathrm{y}}{ }^{*} \\
\mathrm{Rad}\end{array}$ & $\begin{array}{l}\theta_{\mathrm{C}, \mathrm{u}}{ }^{*} \\
\mathrm{rad}\end{array}$ & & $\begin{array}{l}\mathrm{M}_{\mathrm{Cmax}} \\
\mathrm{kNm}\end{array}$ \\
\hline RSG-M & 4891.3 & 0.021 & 0.034 & 1.6 & 77.1 \\
\hline RIS-FB-M & 6011.1 & 0.017 & 0.025 & 1.4 & 108.0 \\
\hline RIP-M & 5806.8 & 0.018 & 0.028 & 1.6 & 74.3 \\
\hline RIP-M2 & 6541.2 & 0.012 & 0.013 & 1.1 & 72.9 \\
\hline KSG-M & 6031.6 & 0.009 & 0.023 & 2.5 & 53.3 \\
\hline KIS-M & 4115.0 & 0.020 & 0.033 & 1.6 & 78.4 \\
\hline KIS-FB-M & 6432.3 & 0.016 & 0.029 & 1.8 & 102.9 \\
\hline KIP-M & 7863.9 & 0.010 & 0.019 & 2.0 & 90.0 \\
\hline KIP-FB-M & 6956.5 & 0.015 & 0.025 & 1.6 & 116.7 \\
\hline
\end{tabular}

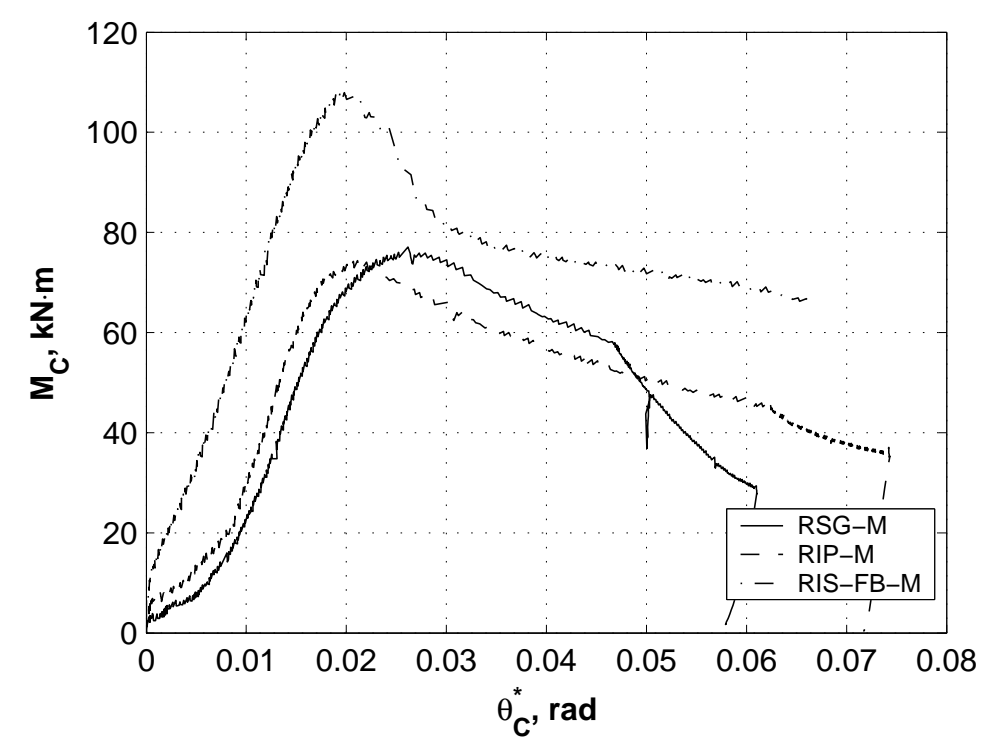

(a)

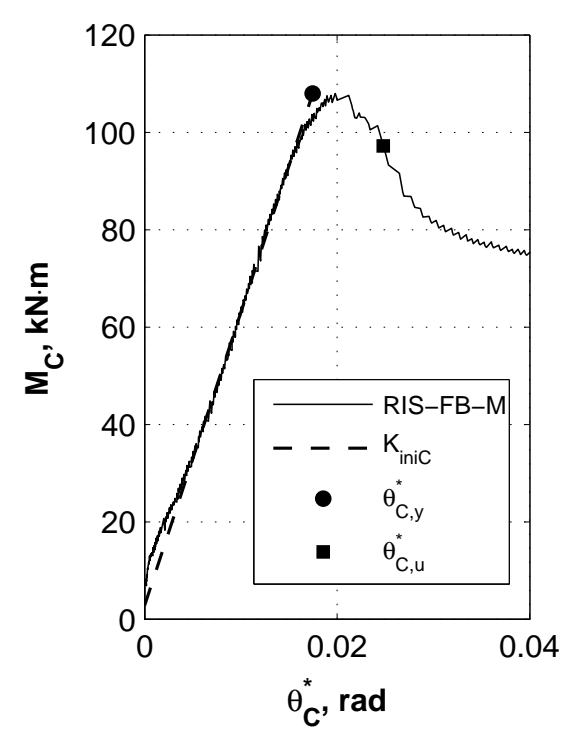

(b)

Figure 8. Comparative Results from Monotonic Tests for Ridge Joints (a) and Graphical Representation of Initial Stiffness, Yield and Ultimate Rotations for the RIS-FB-M Specimen (b)

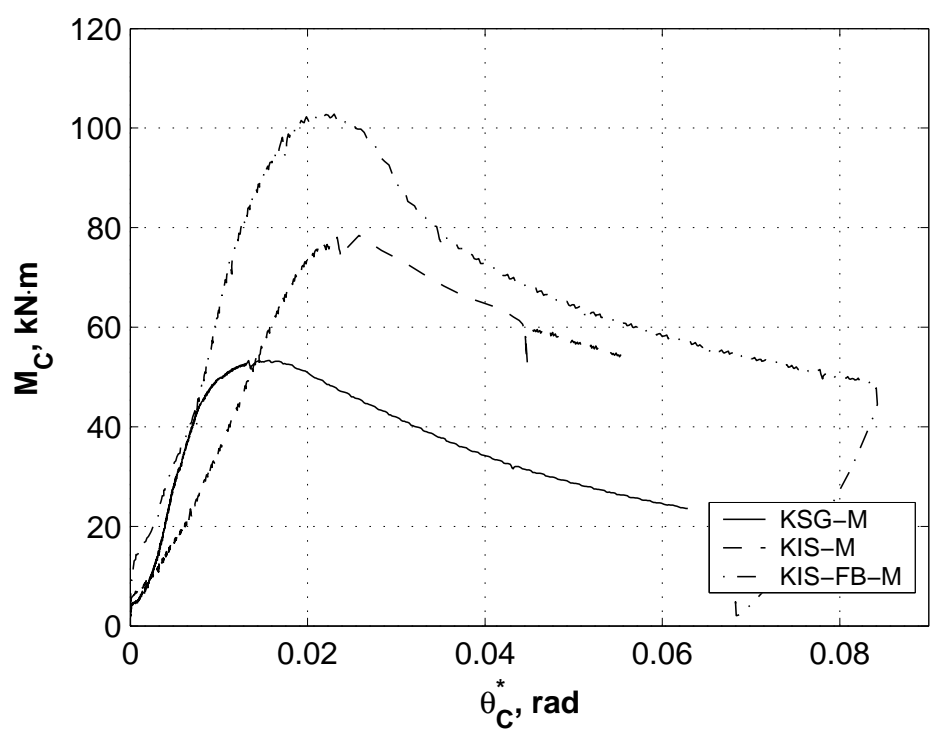

Figure 9. Comparative Results from Monotonic Tests for Knee Joints 


\subsection{Cyclic Tests}

In the case of cyclic loading, failure of specimens started by elongation of bolt holes. Compared to monotonic loading, in the case of cyclic loading the phenomenon was amplified due to the repeated and reverse loading. However, the failure occurred also by local buckling, as in monotonic tests, but at the repeated reversals, the buckling occurred alternately on opposite sides of the profile. This repeated loading caused the initiation of a crack at the corner of the $\mathrm{C}$ profile, in 2-3 cycles following the buckling, closed to the point where the first buckling wave was observed in the flange.

The crack gradually propagated through the flange and web, causing an important decrease of the load bearing capacity in each consecutive cycle.

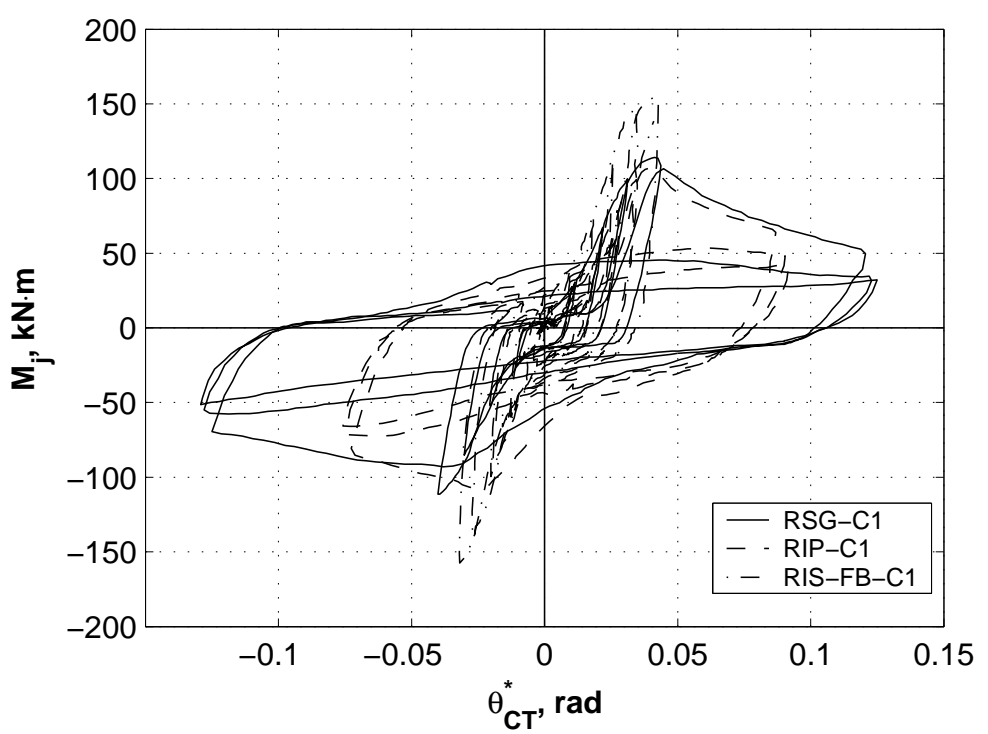

Figure 10. Comparative Results from Cyclic Tests on Ridge Specimens

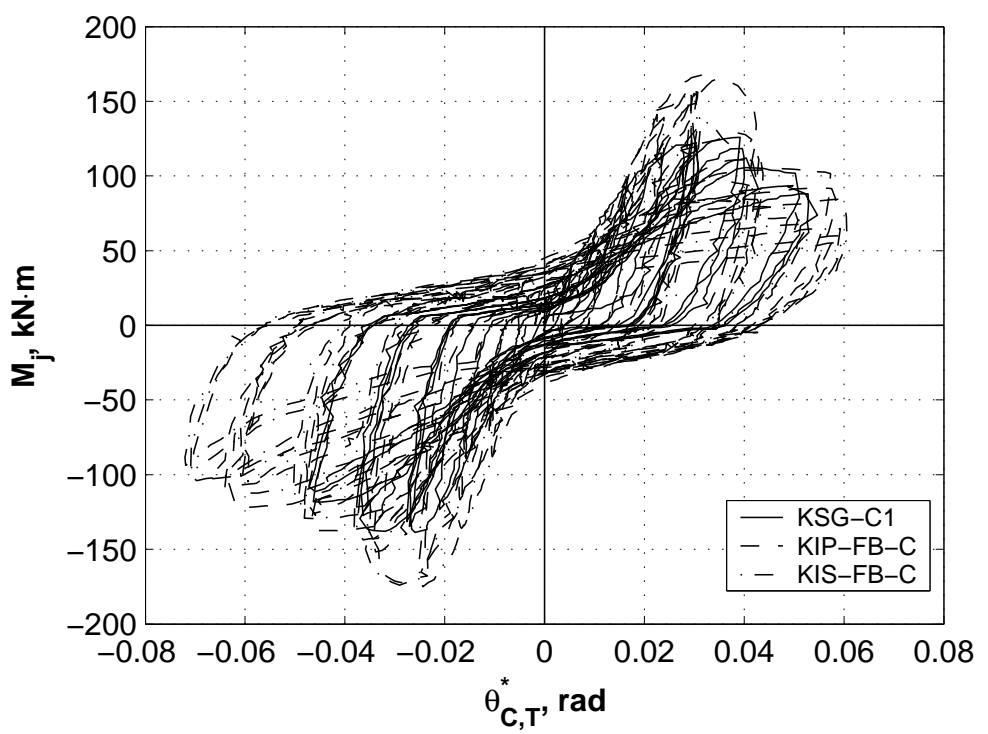

Figure 11. Comparative Results from Cyclic Tests on Knee Specimens 
Table 3. Cyclic Results: Parameters of Connection Moment-Rotation Curves

\begin{tabular}{|c|c|c|c|c|c|}
\hline Specimen & $\begin{array}{l}\mathrm{K}_{\text {iniC }} \\
\mathrm{kNm} / \mathrm{rad}\end{array}$ & $\begin{array}{l}\theta_{\mathrm{C}, \mathrm{y}}{ }^{*} \\
\mathrm{rdd}\end{array}$ & $\begin{array}{l}\theta_{\mathrm{C}, \mathrm{u}}{ }^{*} \\
\mathrm{rad}\end{array}$ & $\mu$ & $\begin{array}{l}\mathrm{M}_{\mathrm{Cmax}} \\
\mathrm{kNm}\end{array}$ \\
\hline \multirow[t]{2}{*}{ RSG-C1 } & 5060.0 & 0.017 & 0.028 & 1.7 & 78.8 \\
\hline & -5400.3 & -0.019 & $*$ & $*$ & -76.8 \\
\hline \multirow[t]{2}{*}{ RSG-C2 } & 4502.9 & 0.018 & 0.028 & 1.6 & 76.0 \\
\hline & -2792.5 & -0.029 & -0.036 & 1.2 & -78.1 \\
\hline \multirow[t]{2}{*}{ RIS-FB-C1 } & $*$ & $*$ & $*$ & $*$ & 106.9 \\
\hline & $*$ & $*$ & $*$ & $*$ & -108.6 \\
\hline \multirow{2}{*}{ RIS-FB-C2 } & $*$ & $*$ & $*$ & $*$ & 100.2 \\
\hline & $*$ & $*$ & $*$ & $*$ & -111.5 \\
\hline \multirow[t]{2}{*}{ RIP-C1 } & 6642.1 & 0.014 & $*$ & $*$ & 73.8 \\
\hline & -6585.1 & -0.013 & $*$ & $*$ & -74.7 \\
\hline \multirow[t]{2}{*}{ KSG-C1 } & 5395.5 & 0.013 & 0.022 & 1.7 & 82.5 \\
\hline & -6672.4 & -0.015 & -0.028 & 1.9 & -90.9 \\
\hline \multirow[t]{2}{*}{ KSG-C2 } & 5067.6 & 0.014 & 0.022 & 1.5 & 84.5 \\
\hline & -4684.1 & -0.014 & -0.017 & 1.2 & -76.8 \\
\hline \multirow[t]{2}{*}{ KIS-FB-C } & 6914.7 & 0.014 & 0.021 & 1.5 & 102.3 \\
\hline & -9201.5 & -0.012 & -0.023 & 2.0 & -114.4 \\
\hline \multirow[t]{2}{*}{ KIP-FB-C } & 10051.8 & 0.012 & 0.026 & 2.1 & 102.2 \\
\hline & -8193.5 & -0.011 & -0.021 & 1.9 & -105.1 \\
\hline
\end{tabular}

$*$ results not available due to faulty data acquisition

The hysteretic M- $\theta$ curves show a stable behaviour up to the yield limit $\left(\theta_{C, y}{ }^{*}\right)$ with a sudden decrease of the load bearing capacity afterwards (Figure 10 and Figure 11). Therefore the low ductility of the specimens must be underlined again. Further, the cycles show the effect of slippage in the joint (i.e. pinching) and strength degradation in repeated cycles. Strength degradation is most significant in the first cycle, while in the consequent ones the behaviour is more stable.

In order to obtain connection characteristics under cyclic loading, an unstabilised envelope was first determined, by considering the points corresponding to maximum moment in each cycle. Based on envelope curves, connection strength, rotation capacity and ductility have been determined following a procedure identical to the one used in the case of monotonic specimens, and are reported in Table 3. Again, joints without flange bolts were weaker.

\section{THE COMPONENT METHOD}

The component method is a general procedure for the design of the strength and stiffness of joints in building frames, and is implemented in EN1993-1-8 [9]. The procedure is primarily intended for heavy-gauged construction. Its application to joints connecting light-gauge members is investigated in the present paper.

Application of the component method requires the following steps (Jaspart et al. [12]):

- identification of the active components within the joint

- evaluation of the stiffness and strength of individual components

- assembly of the components in order to evaluate stiffness and strength of the whole joint 
Based on the conclusions of the experimental programme, the present study investigates only joints with both web and flange bolts (RIS-FB-M, KIS-FB-M, and KIP-FB-M). Qualitative FEM simulation (see Figure 12) showed that in the case of specimens with bolts on the web only there is a stress concentration in the web, which causes premature local buckling failure. The FEM simulation also demonstrated that load distribution in the bolts is not linear. In fact, due to member flexibility and local buckling, the connected members do not behave as rigid bodies, and the centre of rotation of web bolts does not coincide with the centroid of web bolts. The centre of rotation of the connection is shifted towards the outer bolt rows (see Figure 13), whose corresponding force is an order of magnitude higher than the force in the inner bolts. Considering this observation, only the outer bolt group was considered for determination of connection characteristics using the component method. This assumption significantly differ in comparison with the behaviour models considered in the papers of the list of reference, which, all, consider the centroid of the bolt group as the rotation centre.

The centre of compression of the connection was considered at the exterior flange of the cold-formed member (see Figure 13), similarly with the model used for design of bolted connections with angle flange cleats in EN1993-1-8 [9]. There are a total of four bolt rows, of which three bolt rows are in the "tension" zone. The following components were identified and used to model the connection stiffness and strength:

- Cold-formed member flange and web in compression. Only the strength of this component was considered, while stiffness was considered infinite (similarly with Lim and Nethercot [1])

- Bolts in shear

- Bolts in bearing on the cold-formed member

- Bolts in bearing on the bracket

The stiffness and strength of all these components are readily available in EN1993-1-8 [9], only minor adjustments being required for the case of the particular case considered here. In order to facilitate comparison with the experimental results, the measured geometrical characteristics and strength (yield stress $f_{y}=452 \mathrm{~N} / \mathrm{mm}^{2}$, and tensile strength $f_{u}=520 \mathrm{~N} / \mathrm{mm}^{2}$ ) were considered in the case of the cold-formed member. Nominal characteristics were used for the bracket and bolt characteristics, as experimental data was not available. Partial safety factors equal to unity were considered in all cases.

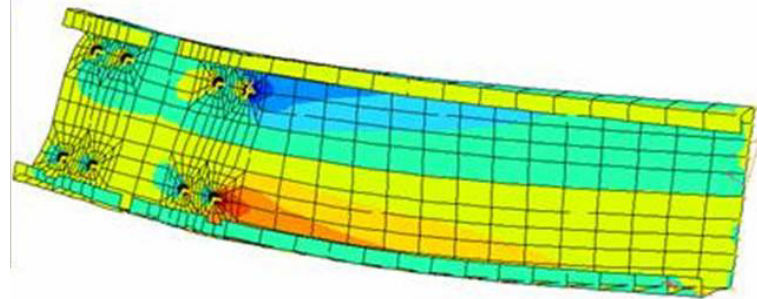

(a)

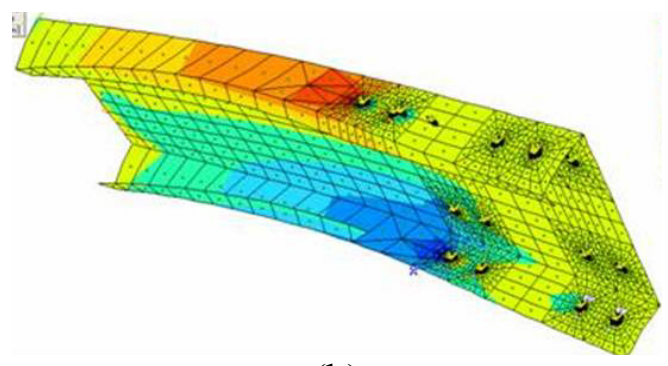

(b)

Figure 12. Stress Concentration in the Case of Specimens with Web Bolts Only (a), and Both Web and Flange Bolts (b) 


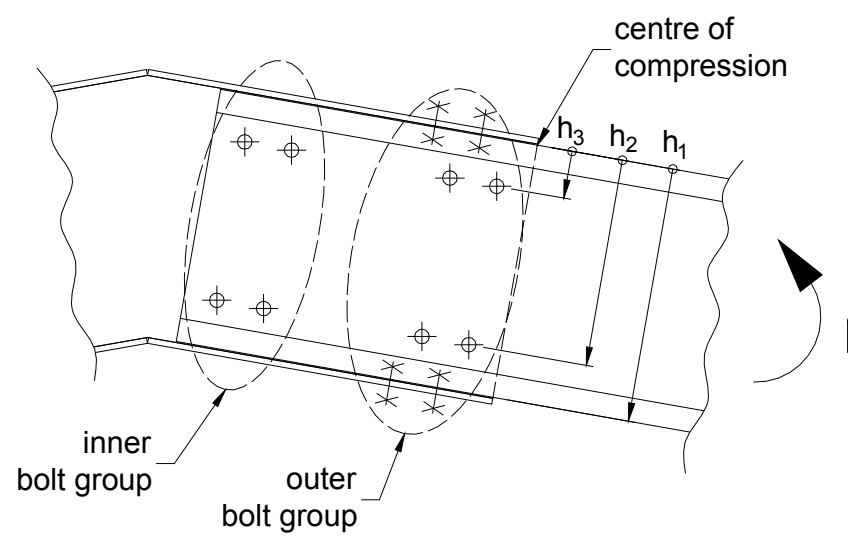

Figure 13. Bolt Groups Considered in Analysis

Only three components were considered to contribute to the stiffness of the connection: bolts in shear (denoted $k_{v, f}$ for flange bolts and $k_{v, w}$ for web bolts), bolts in bearing on cold-formed member (denoted $k_{b, c f f}$ for flange bolts and $k_{b, c f w}$ for web bolts), and bolts in bearing on the bracket (denoted $k_{b, b f}$ for flange bolts and $k_{b, b w}$ for web bolts), see Figure 14a. Formulas for determination of stiffness coefficients are available in EN1993-1-8 [9]. For each of the bolt rows $r$, an effective stiffness coefficient $k_{\text {eff,r }}$ is determined, by combining the individual stiffness coefficients using the following relationship (EN1993-1-8 [9], see Figure 14b):

$$
k_{e f f, r}=\frac{1}{\sum_{i} \frac{1}{k_{i, r}}}
$$

The effective stiffness coefficients of the bolt rows in "tension" zone are replaced by an equivalent spring $k_{e q}$ (EN1993-1-8 [9], see

Figure 14Figure 14c):

$k_{e q}=\frac{\sum_{r} k_{e f f, r} h_{r}}{z_{e q}}$

where $h_{r}$ is the distance between bolt row $r$ and the centre of compression; $z_{e q}$ is determined using Eq. 3.

$z_{e q}=\frac{\sum_{r} k_{e f f, r} h_{r}{ }^{2}}{\sum_{r} k_{e f f, r} h_{r}}$

Finally, the initial connection stiffness is determined as (see Figure 14d):

$$
S_{j, i n i}=\frac{E z_{e q}^{2}}{\sum_{i} 1 / k_{i}}
$$




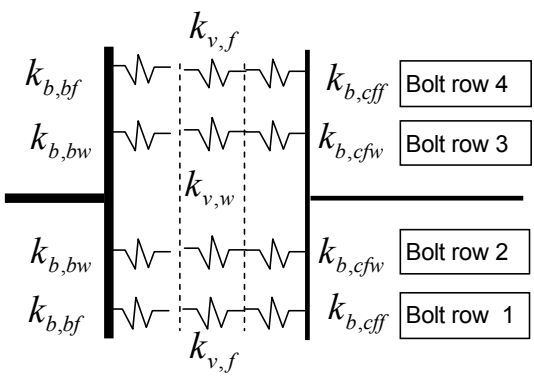

(a)

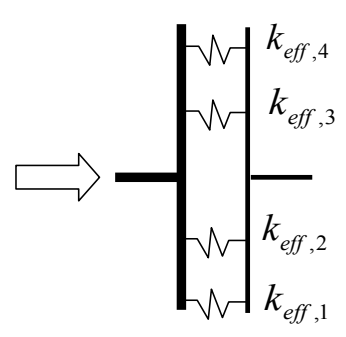

(b)

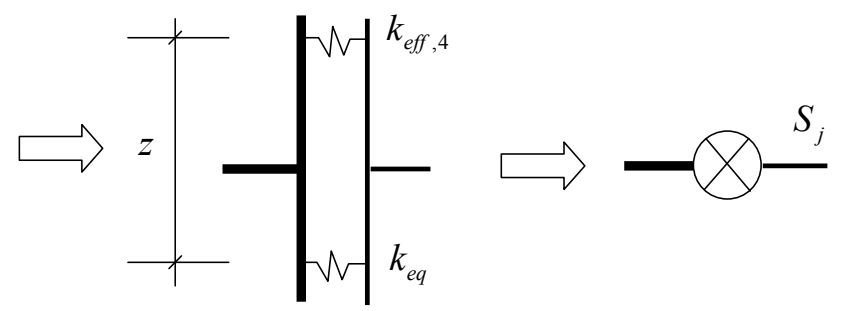

(c)

(d)

Figure 14. Main Steps in the Assembly of Components for Determination of Connection Stiffness

The moment resistance of the bolted connection was determined using a two-step procedure. In the first step, only components related to bolt resistance were included in order to determine the moment resistance of the bolted connection $M_{C, R d}^{b}$. In a second step, the connection moment resistance was obtained as the minimum of the moment resistances of the bolted connection $M_{C, R d}^{b}$ and the connected cold-formed member $M_{\text {beam,Rd: }}$

$M_{C, R d}=\min \left(M_{C, R d}^{b}, M_{\text {beam }, R d}\right)$

The adopted approach for determination of connection moment resistance allows to easily determine if the connection is full-strength or partial strength.

The moment resistance of the bolted connection was determined as (EN1993-1-8 [9]):

$M_{C, R d}^{b}=\sum_{r} F_{t r, R d} h_{r}$

where $F_{t r R d}$ is the effective tension resistance of bolt row $r$ (minimum value of components related to bolt row $r) ; h_{r}$ is the distance between bolt row $r$ and the centre of compression.

The moment resistance of the cold-formed member $M_{\text {beam,Rd }}$ was determined using measured geometrical and mechanical characteristics, using effective cross-section modulus.

It was considered appropriate to use a linear distribution of forces on bolts in the case of a connection to light-gauge members. Therefore, the effective tension resistance of bolt rows was limited according to the following relationship:

$$
F_{t r, R d} \leq F_{t 1, R d} \frac{h_{r}}{h_{1}}
$$


where $F_{t 1, R d}$ is the effective tension resistance of bolt row 1 (farthest from the centre of compression); $h_{1}$ is the distance between bolt row 1 and the centre of compression.

Table 4 and Table 5 present resistance and stiffness of bolt rows. The weakest component of flange bolts is bearing on cold formed member, while in the case of web bolts it is bearing on bracket (see Table 4). The difference is due to the fact that bolts are in simple shear on flanges and in double shear on web, as well as due to different number of bolts on flanges ( 4 bolts per row) and web (2 bolts per row). The main contribution to the flexibility of the connection is bearing on the cold-formed member, as well as bearing on bracket in the case of web bolts (see Table 5).

The configuration of the outer group of bolts being the same in the case of all three specimens with web and flange bolts (RIS-FB-M, KIS-FB-M, KIP-FB-M), a single set of analytical connection properties were determined. A comparison of experimental vs. analytical characteristics of connections (stiffness and moment resistance) is presented in Table 6. Generally a fair agreement between experimental and analytical stiffness of the connection can be observed. Larger experimental values of stiffness can be explained by the fact that the contribution of the inner bolt group was ignored in the analytical model. The stiffness of the connection is considerably lower than the EN1993-1-8 limits for classification of joints as rigid $\left(25 E I_{b} / L_{b}\right)$, which amounts to 25256 $\mathrm{kN} / \mathrm{m}$ (considering the beam span $L_{b}$ equal to frame span and using gross moment of inertia $I_{b}$ ). Therefore, these types of connections are semi-rigid, and their characteristics need to be taken into account in the global design of frame.

Table 4. Resistance of Connection Components

\begin{tabular}{|c|c|c|c|c|}
\hline \multirow{2}{*}{$\begin{array}{c}\text { Bolt } \\
\text { row }\end{array}$} & $\begin{array}{c}\text { Bolts in } \\
\text { shear, } \mathrm{kN}\end{array}$ & $\begin{array}{c}\text { Bolts in bearing on the } \\
\text { cold-formed member, } \\
\mathrm{kN}\end{array}$ & $\begin{array}{c}\text { Bolts in bearing } \\
\text { on the bracket, } \\
\mathrm{kN}\end{array}$ & $\begin{array}{c}\text { Bolt-row resistance } \\
F_{t r, R d,} \\
\mathrm{kN}\end{array}$ \\
\hline 1 & 361.4 & 290.6 & 527.0 & 290.6 \\
\hline 2 & 361.4 & 290.6 & 288.0 & 288.0 \\
\hline 3 & 361.4 & 290.6 & 288.0 & 288.0 \\
\hline 4 & 361.4 & 290.6 & 527.0 & 290.6 \\
\hline
\end{tabular}

Table 5. Stiffness of Connection Components

\begin{tabular}{|c|c|c|c|c|}
\hline \multirow{2}{*}{$\begin{array}{c}\text { Bolt } \\
\text { row }\end{array}$} & $\begin{array}{c}\text { Bolts in } \\
\text { shear, mm }\end{array}$ & $\begin{array}{c}\text { Bolts in bearing on the } \\
\text { cold-formed member, } \\
\mathrm{mm}\end{array}$ & $\begin{array}{c}\text { Bolts in bearing } \\
\text { on the bracket, } \\
\text { mm }\end{array}$ & $\begin{array}{c}\text { Bolt-row effective } \\
\text { stiffness } k_{\text {eff, },}, \\
\mathrm{mm}\end{array}$ \\
\hline 1 & 2.286 & 0.7785 & 1.3886 & 0.4095 \\
\hline 2 & 2.286 & 0.7785 & 0.7714 & 0.3313 \\
\hline 3 & 2.286 & 0.7785 & 0.7714 & 0.3313 \\
\hline 4 & 2.286 & 0.7785 & 1.3886 & 0.4095 \\
\hline
\end{tabular}

Table 6. Experimental vs. Analytical Connection Characteristics

\begin{tabular}{|c|c|c|c|c|}
\hline \multirow{2}{*}{ Specimen } & \multicolumn{2}{|c|}{ Initial stiffness, $K_{\text {iniC }}[\mathrm{kNm} / \mathrm{rad}]$} & \multicolumn{2}{c|}{ Moment resistance, $M_{C},[\mathrm{kNm}]$} \\
\cline { 2 - 5 } & experimental & analytical & experimental & analytical \\
\hline RIS-FB-M & 6011 & 5224 & 108.0 & 117.8 \\
\hline KIS-FB-M & 6432 & 5224 & 102.9 & 117.8 \\
\hline KIP-FB-M & 6957 & 5224 & 116.7 & 117.8 \\
\hline
\end{tabular}


The moment resistance of the bolted connection $M_{C, R d}^{b}$ determined by the component method amounted to $193.9 \mathrm{kNm}$, which was larger than the moment resistance of the cold-formed member $M_{\text {beam,Rd, }}$, amounting $117.8 \mathrm{kNm}$. Therefore, this type of connection is a full-strength one. This was demonstrated also by the experimental results, failure mode being local buckling of the cold-formed member.

\section{FULL SCALE TESTS ON PITCHED-ROOF PORTAL FRAMES}

\subsection{Test Setup}

Following experimental tests on cold-formed joints, two full-scale tests on frames were performed. Frame dimensions were chosen identical to the ones in the initial design used to establish the dimensions of tested joints. Considering the poor performance of joints with web bolts only, RIS-FB and KIS-FB configurations (with both web and flange bolts) were used for frame construction. Pinned supports were used at the column bases. The objective of the full-scale tests was to assess the performance of pitched-roof cold-formed portal frames with moment-resisting joints under lateral loading, with particular emphasis on earthquake loading.

The test setup consisted of two frames in upward position, located $1.5 \mathrm{~m}$ apart. Tie bracing was provided between the two frames in order to provide out-of plane stability. The purlins were installed on the girders, but no side rails were provided on the columns. The schematic representation of test setup is shown in Figure 15. A reaction frame was used to apply lateral load.

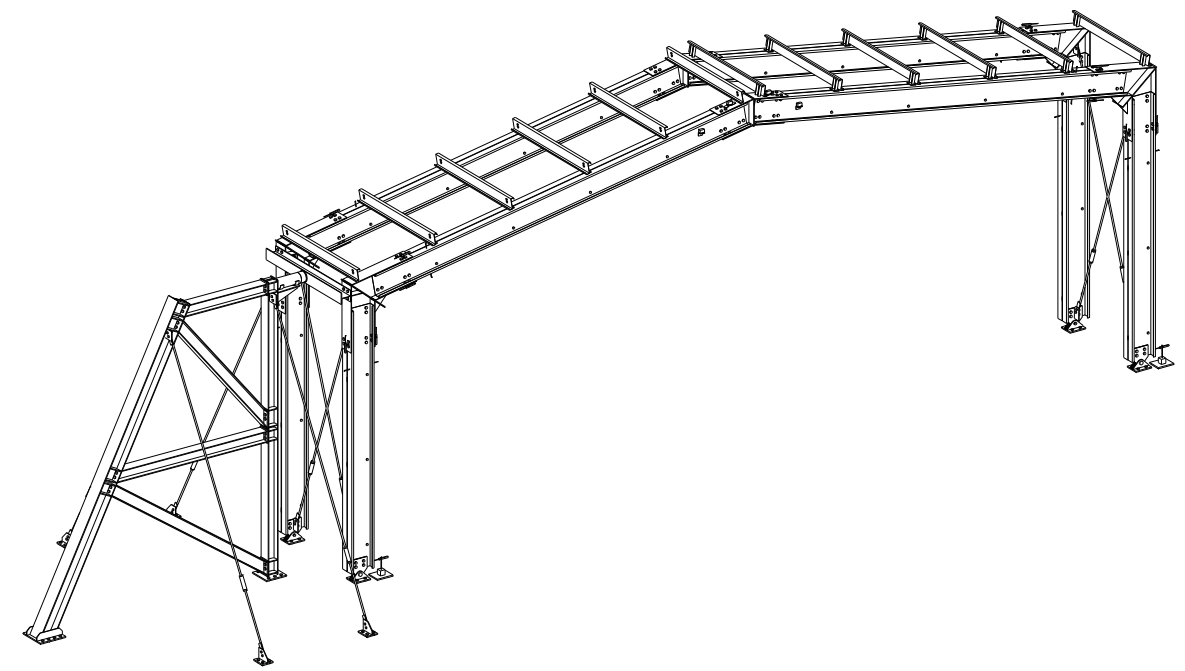

Figure 15. Experimental Test Setup for Full-scale Tests

In the case of the first test $(\mathrm{C} 1)$, only lateral loading was applied. For the second test $(\mathrm{C} 2)$, gravity loading corresponding to seismic design situation (permanent and a 0.3 fraction of the snow load) was applied, followed by increasing lateral load up to failure. Total gravity loading amounted to $31.2 \mathrm{kN}$ per frame, and was applied using 30 corrugated steel sheets laid on the purlins. A load cell was used in order to measure lateral load applied through a hydraulic jack. Frames were instrumented with displacement transducer to measure lateral in-plane and out-of plane displacements at the eaves, deflections at the ridge, as well as connection rotations. 


\subsection{Test Results and Comparison to Numerical Model}

Experimental tests on ridge and eaves joints showed that bolted connections of back-to-back channel cold-formed members are semi-rigid, even when bolts are provided not only on the web, but also on the flanges of the channel section. Therefore, deformations can be underestimated if connections are assumed rigid for global frame analysis. In order to assess the influence of connection stiffness and post-buckling resistance, three frame models were analysed (see Figure 16). A nonlinear static analysis under increasing lateral load was applied to the models, and the results were compared to experimental ones.

The first model was a conventional model, where connections were considered rigid. Nominal geometrical characteristics were used to model members. Finite dimensions of brackets were taken into account. Local buckling of members was modelled by rigid-plastic hinges located at the extremities of cold-formed members. an analytically determined moment capacity $\left(M_{c}=117.8 \mathrm{kNm}\right)$ was considered.

The second model (M2, see Figure 16b) was obtained from model M1 by adopting an elastic perfectly-plastic model of the connection moment-rotation response. The initial stiffness $\left(K_{\text {ini }}=5224 \mathrm{kNm} / \mathrm{rad}\right)$ and moment capacity $\left(M_{c}=117.8 \mathrm{kNm}\right)$ were the ones obtained using the analytical procedure described above (see Table 6).

In the case of the third model (M3, see Figure 16c), the elasto-plastic model was enhanced following two directions. The first one was related to connection behaviour under small loads, when experimental evidence showed a very stiff initial response. This response is attributed to wedging and friction between the cold-formed profiles and the bracket. Consequently, a rigid response was assumed before "slipping" up to moment $M_{s}$ (see Figure 17a). The value of the "slipping" moment $M_{S}$ was estimated based on experimental results, a value of $15 \%$ from the connection moment capacity being adopted. Following the initial rigid behaviour, the connection model consists of an elastic response at the initial stiffness $K_{\text {iniC }}$ (determined using the component method), up to the connection moment capacity $M_{C}$.

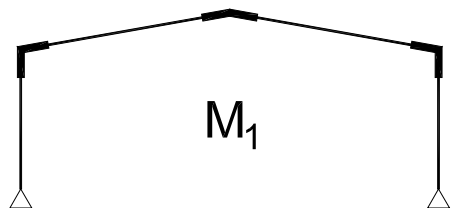

(a)

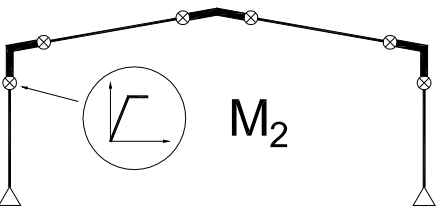

(b)

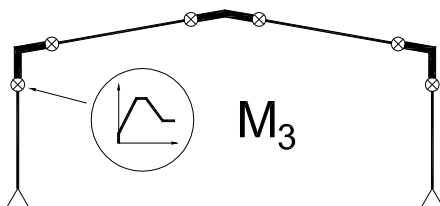

(c)

Figure 16. Considered Structural Models: Rigid Connections - M1 (a), Elastic-Perfectly Plastic Connections - M2 (b), and Degrading Connections - M3 (c)

The second enhancement of the model consisted in post-elastic response. The plastic rotation (plateau) was determined assuming an ultimate rotation $\theta_{C u}$ equal to 1.4 times the yield rotation $\theta_{C y}$. The softening branch was determined by considering a drop of moment capacity to $50 \%$ from the maximum one, at a rotation $\theta_{C r}$ of 4.0 times the yield rotation (see Figure 17a). The same moment-rotation characteristics were used for all connections (for both beams and columns). The influence of axial force on the stiffness and moment resistance of the connection were ignored. A comparison between the analytical model and the experimental moment-rotation curves is shown in Figure $17 \mathrm{~b}$. 
Figure 18a shows a global view of the $\mathrm{C} 1$ frame (tested under horizontal loading only) after the test. The frame response during the test was characterised by an almost linear response up to the first local buckle of the beam at the connection 2 (see Figure 18b, Figure 19, and Figure 20a), followed by a rapid loss of global frame resistance. The final collapse mechanism consisted of hinging of the beam at connections 2 and 5 (see Figure 20b) near the eaves.

A comparison of the experimental and numerical lateral force - deformation curves for the $\mathrm{C} 1$ frame is shown in Figure 19. The force corresponds to one of the two frames from the experimental setup, assuming the force equally distributed between the two frames. It can be observed that the rigid model (M1) provides a good approximation of the initial response of the frame up to lateral forces of about $10 \mathrm{kN}$. At larger forces, model M2, with semi-rigid connections, provide a better approximation of the experimental response. The M3 model, incorporating both the initial rigid response and subsequent semi-rigid behaviour shows the best agreement to the experimental results. The same pattern of member hinging as in the one observed in the experiment is obtained for the numerical model (see Figure 20b for the case of the M3 model). The M3 model captures well the initial and post-buckling response. M2 model overestimates lateral deformations. All three models slightly underestimate the global frame resistance.

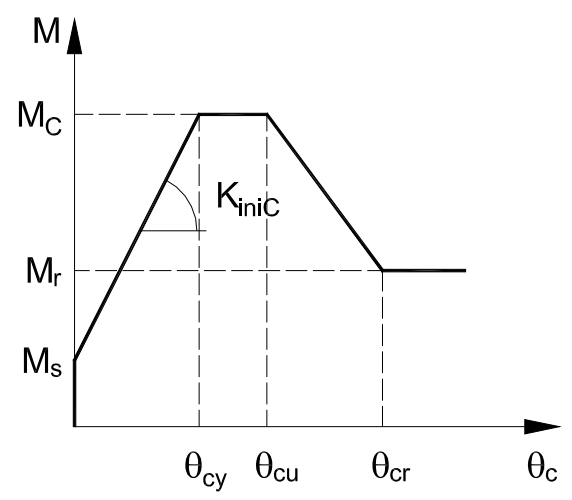

(a)

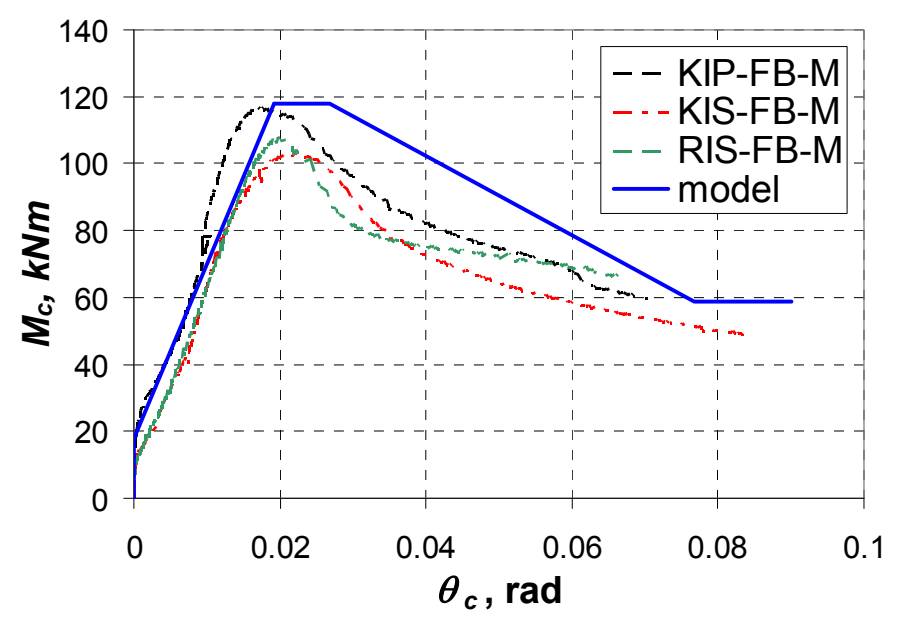

(b)

Figure 17. Parameters of the M3 Connections Model (a), and Experimental and Analytical M3 Model of Connection Moment-rotation Relationship (b)

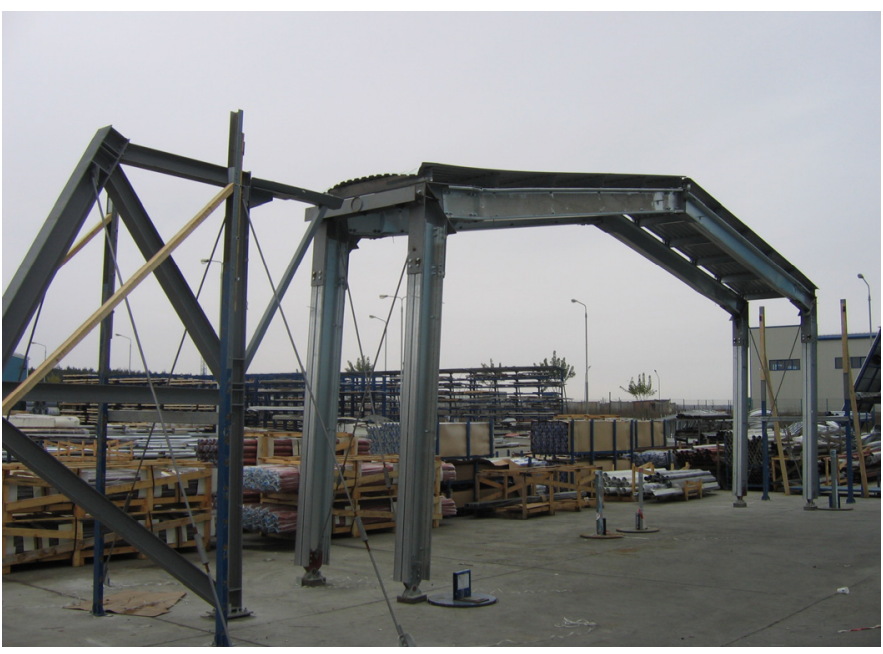

(a)

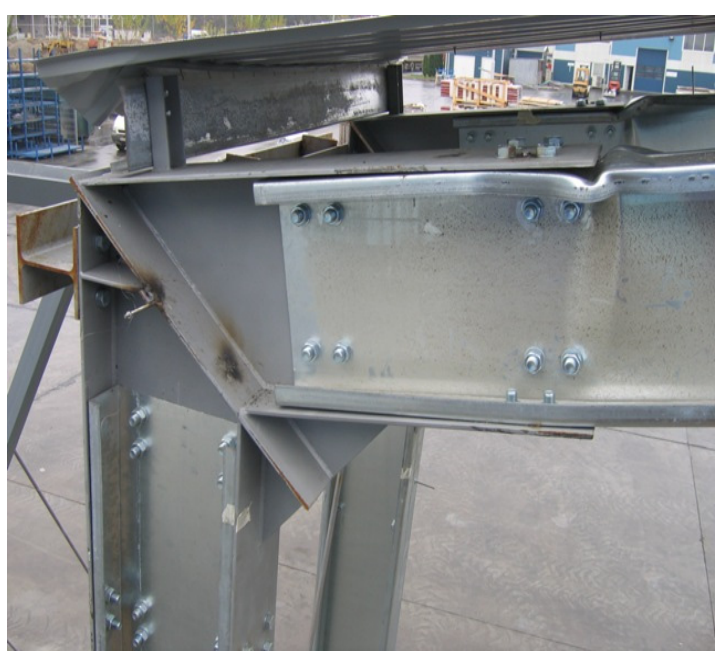

(b)

Figure 18. C1 Frame: Global View (a) and Local Buckling of the Left Beam Connection (b) 


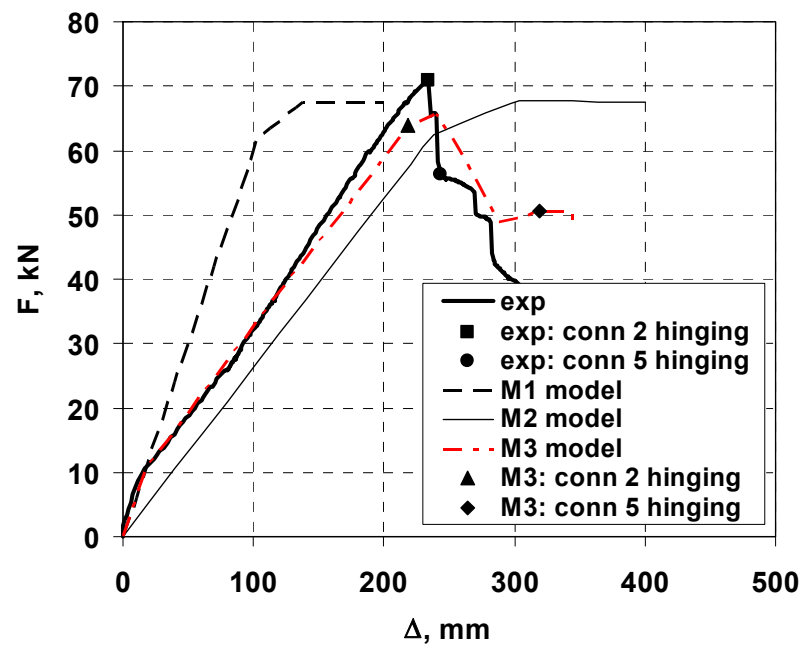

Figure 19. Frame C1: Experimental vs. Numerical Lateral Force - Deformation Curves

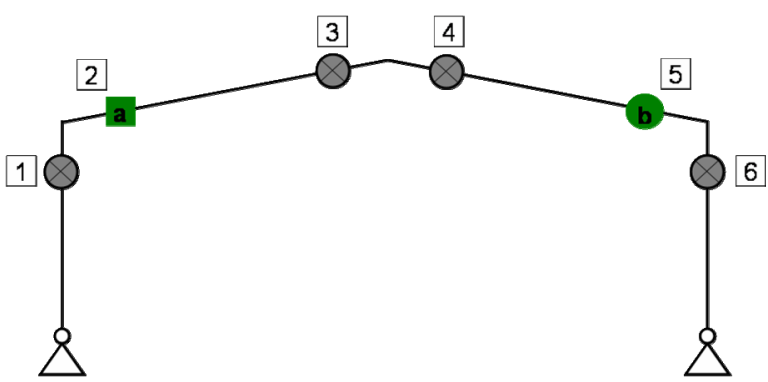

(a)

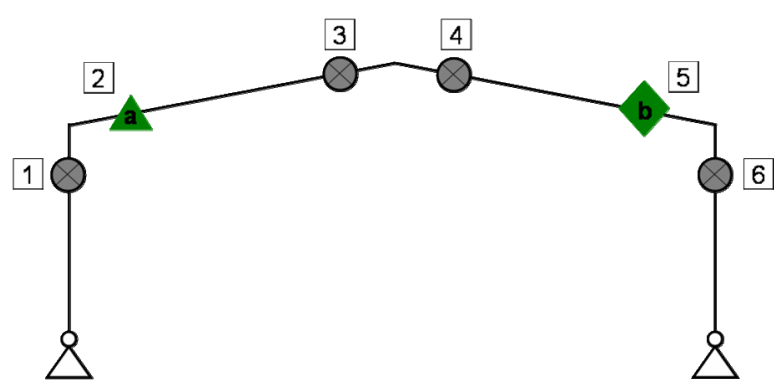

(b)

Figure 20. Frame C1: Position of Local Buckling Observed Experimentally (b) and in the Numerical Model (c)

In the case of the $\mathrm{C} 2$ frame, gravity loading corresponding to seismic design situation was first applied, followed by increasing lateral loading up to complete failure of the frame. Figure 21a shows a view of the frame during loading. The global force-deformation response was very similar to the frame $\mathrm{C} 1$ up to $10-15 \mathrm{kN}$ lateral loading. For larger lateral loading, the stiffness of the $\mathrm{C} 2$ frame was slightly larger than the one of the $\mathrm{C} 1$ frame. However, the global resistance under horizontal loading was smaller in the case of the $\mathrm{C} 2$ frame. The ultimate capacity was attained at the first local buckle in the beam near the right eaves (connection 5, see Figure 23a), when the lateral force resistance dropped suddenly. It was followed by a combined local buckling and lateral-torsional buckling of one of the columns at the mid-height (see Figure 21a and Figure 23a). Finally, local buckling of the beam at the left eaves was observed (at connection 2, see Figure 23a).

A comparison of the experimental and numerical lateral force - deformation response of the $\mathrm{C} 2$ frame is shown in Figure 22. As in the case of frame C1, The M1 model (with rigid connections) provides a good approximation of the initial response of the frame, up to lateral forces of about 10 $\mathrm{kN}$. For larger forces, the M2 model, accounting for semi-rigid connection response, shows a better approximation of experimental response. The M3 model shows the best agreement between the numerical and experimental results. All numerical models overestimate the global frame resistance under lateral loading. There are two factors that are believed to have contributed to this situation: (1) the numerical model did not consider buckling of the column and (2) the influence of axial forces was neglected when determining connection moment resistance. Higher axial forces are present in the right column under combined effect of gravity loading and lateral loading due to the effect of overturning. While the location of the first local buckle was correctly predicted by the numerical model (at connection 5, see Figure 23a and Figure 22b), column hinging (due to combined local 
and flexural-torsional buckling) observed in the experimental test was not confirmed by numerical models. Column hinging can be explained by neglected influence of axial force, combined with the effect of no lateral restraining at column flanges by side rails. Both of these effects were present in the experimental setup, but not in the numerical model.

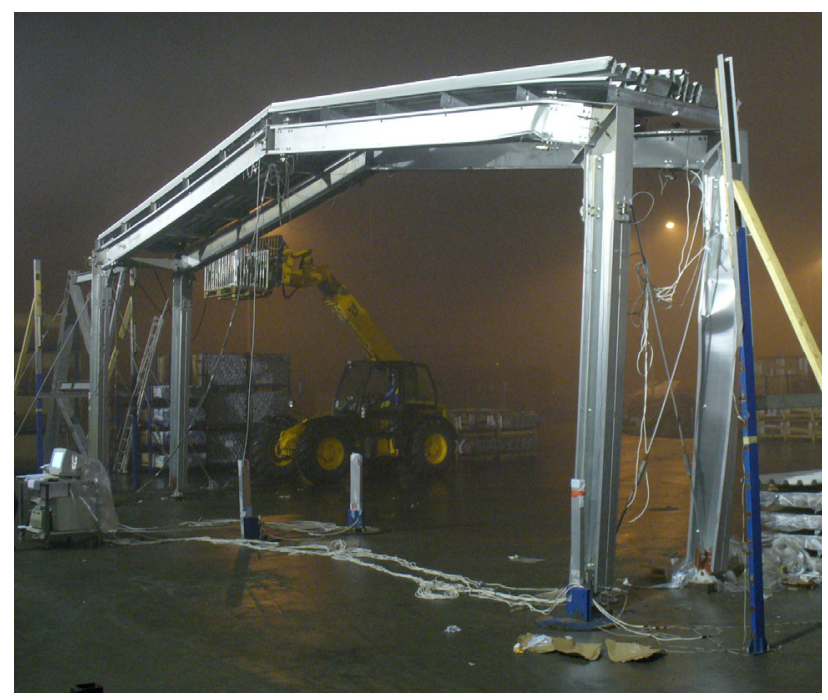

(a)

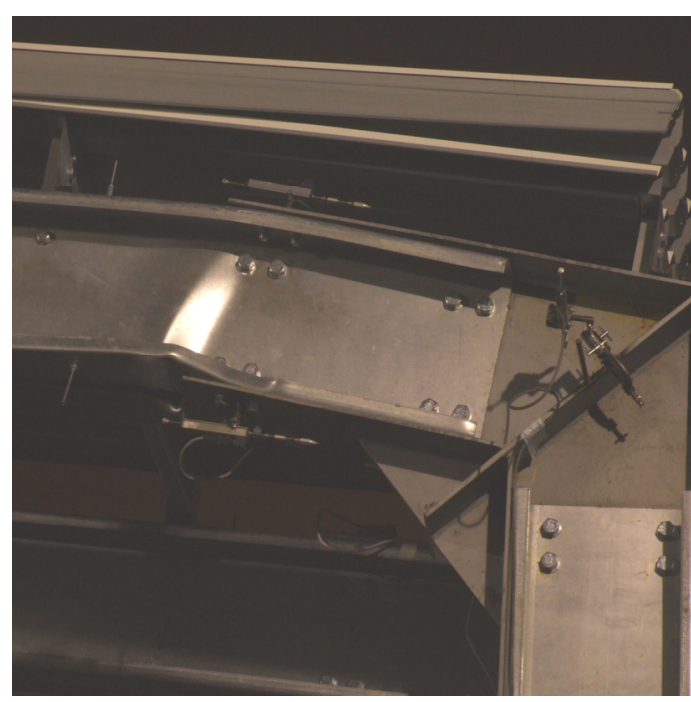

(b)

Figure 21. C2 Frame: Global View (a) and Local Buckling of the Right Beam Connection (b)

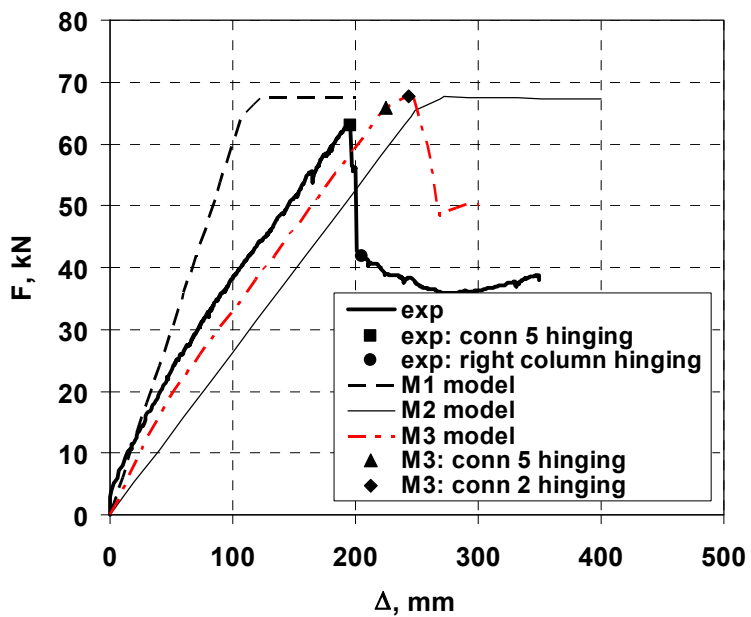

Figure 22. Frame C2: Comparison of Experimental and Numerical Lateral Force Deformation Curves

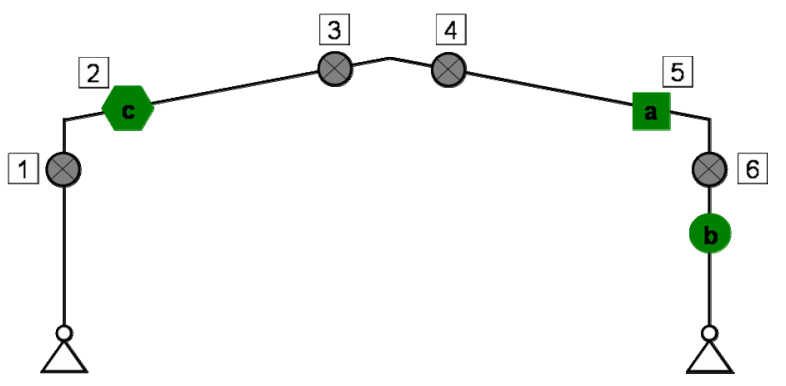

(a)

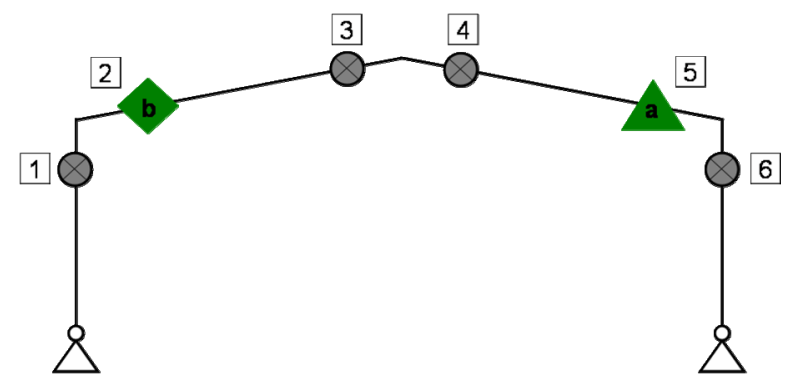

(b)

Figure 23. Frame C2: Position of Local Buckling Observed Experimentally (b) and in the Numerical Model (c) 
It can be concluded that the M3 model seems to provide the best agreement with the experimental results, if initial stiffness, lateral resistance, and post-buckling response are envisaged. The global frame resistance under lateral loads drops quickly after the first local buckling, when the maximum force is reached. This behaviour is attributed to the similar rapid drop in moment resistance of cold-formed cross-sections, as well as to the low redundancy of the frame. Therefore, for practical cases, the response to the first local buckle in members is important, which can be estimated using a simpler frame model, incorporating only the semi-rigid connection response, eventually an elastic perfectly plastic model. The Global frame stiffness determined using the bilinear moment-rotation characteristics obtained analytically by the component method is smaller than the experimental stiffness. The real initial stiffness of the connection may be higher at low moments, due to restraining provided by flanges of the bracket element and/or by the inner bolt group. The M3 connection model is capable of representing this higher stiffness and provides the closest match between experimental and numerical frame stiffness values.

\section{CONCLUSIONS}

This study suggests that the classical calculation model for connections, assuming the centre of rotation to be located at the centroid of the bolt group and a linear distribution of the forces on each bolt, is inappropriate for frames featuring cold-formed members. The force distribution is unequal due to the flexibility of the connected members. In fact, the force is an order of magnitude bigger in the outer bolt rows compared to most inner ones. A connection with bolts only on the web causes concentrated forces in the web of the connected member and leads to premature web buckling, reducing the joint moment capacity. These type of connections are always partial strength. If the load bearing capacity of the connected beam is to be matched by the connection strength, bolts on the flanges become necessary. The ductility of the connection is reduced both under monotonic and cyclic loads and the design, including the design for earthquake loads, should take into account only the conventional elastic capacity. Because there is no significant post-elastic strength, there are no significant differences in ductility and capacity of cyclically tested specimens compared with the monotonic ones.

The application of the component method implemented in EN1993-1-8 for determination of connection characteristics in the case of cold-formed members is possible with a minimum number of adjustments. For the particular case of connection studied in this paper (with both flange and web bolts), connection characteristics can be determined with a reasonable accuracy if only the outer bolt group of bolts is considered. The components contributing to the stiffness and strength of the connection are: cold-formed member flange and web in compression, bolts in shear, bolts in bearing on the cold-formed member, and bolts in bearing on the bracket. It is considered appropriate to use a linear distribution of forces on bolts in the case of a connection to light-gauge members.

The connection with both flange and web bolts is semi-rigid but full-strength. Therefore the design of light-gauge portal frames with the considered type of connection needs to account for connection flexibility. Connection characteristics obtained using the component method (EN1993-1-8) can be easily incorporated in the structural model, in order to obtain a realistic response under lateral forces. A connection model is developed that captures well both the behaviour in the elastic range and in the post-elastic range.

Though a detailed moment-rotation response representing the initial stiffness, moment resistance and post-buckling response provides the most realistic global response, a simple elastic structural analysis modelling connection stiffness alone can be sufficient for design purpose. Cold-formed steel pitched-roof portal frames of back-to-back channel sections and bolted joints are characterised 
by a rapid degradation of strength after the first local buckling in its members. This behaviour is attributed to the similar rapid drop in moment resistance of cold-formed cross-sections, as well as to the low redundancy of the frame analysed in this study. Therefore, for the considered frame configuration, global strength may be estimated at the attainment of the moment capacity in the most stressed cross-section using an elastic structural analysis. Axial forces can reduce moment resistance of cold-formed members and need to be taken into account.

\section{REFERENCES}

[1] Lim, J.B.P. and Nethercot, D.A., "Stiffness Prediction for Bolted Moment-connections between Cold-formed Steel Members", Journal of Constr. Steel Res., 2004, Vol. 60, Issue 1, pp. 85-107.

[2] Chung, K.F. and Lau, L., "Experimental Investigation on Bolted Moment Connections Among Cold Formed Steel Members", Engineering Structures, 1999, Vol. 21, No. 10, pp. 898-911.

[3] Lim, J.B.P. and Nethercot, D.A., "Ultimate Strength of Bolted Moment-connections between Cold-formed Members", Thin-Walled Structures, 2003, Vol. 41, No. 11, pp. 1019-1039.

[4] Dundu, M., Kemp, A.R., "Strength Requirements of Single Cold Formed Channels Connected Back-to-back", Journal of Constructional Steel Research, 2006, Vol. 62, Issue 3, pp. 250-261.

[5] Yu, W.K., Chung, K.F. and Wong, M.F., "Analysis of Bolted Moment Connections in Cold-formed Steel Beam-column Sub-frames", Journal of Constructional Steel Research, 2005, Vol. 61, Issue 9, pp. 1332-1352.

[6] Lim, J.B.P., "Joint Effects in Cold-formed Steel Portal Frames", University of Nottingham, Ph.D. Thesis, 2001.

[7] Kwon, Y.B., Chung, H.S., and Kim, G.D., "Experiments of Cold-formed Steel Connections and Portal Frames", Journal of Structural Engineering, 2006, Vol. 132, No. 4, pp. 600-607.

[8] Dubina, D., Stratan, A., Ciutina, A., Fulop, L., Nagy, Zs., "Performance of Ridge and Eaves Joints in Cold-formed Steel Portal Frames", Proc. of the 17th int. Specialty Conf., Orlando, Florida, USA, 04-05 Nov. 2004, Univ. of Missouri-Rolla, Ed. R.A. LaBoube, W-W. Yu, pp. 727-742.

[9] EN1993-1-8, "Eurocode 3: Design of Steel Structures - Part 1-8: Design of joints", European Committee for standardization, 2003.

[10] EN 1993-1-3, "Eurocode 3: Design of Steel Structures. Part 1-3: General Rules. Supplementary Rules for Cold-formed Thin Gauge Members and Sheeting", European Committee for Standardization, 2001.

[11] ECCS(1985), "Recommended Testing Procedure for Assessing the Behaviour of Structural Steel Elements under Cyclic Loads", European Convention for Constructional Steelwork, TWG 13 Seismic Design, Report No. 45, 1985

[12] Jaspart, J.P., Steenhuis, M., Anderson, D., "Characterisation of the Joint Properties by Means of the Component Method", Control of Semi-rigid Behaviour of Civil Engineering Structural Connections, COST C1, Proc. of the Int. Conf, Liege, 17-19 September 1998. 